PEDAGOGISK FORSKNING I SVERIGE Vol 27 No 1 (2022) ISSN 1401-6788

\title{
Berättelser i pedagogisk forskning
}

Marie Karlsson

Institutionen för pedagogik, didaktik och utbildningsstudier, Uppsala universitet

\begin{abstract}
Detta temanummer samlar pedagogisk forskning som på olika sätt studerar berättelser och berättande. Med denna introduktion vill jag, förutom att presentera temanumrets fem bidrag, väcka intresse för berättelseforskning inom kunskapsområdet pedagogik då den möjliggör studier av pedagogiska processer som levd erfarenhet på ett sätt så få andra ansatser kan göra anspråk på (Clandinin \& Rosiek, 2006). Texten inleds med en betraktelse över berättelseforskningens tänkbara bidrag inom pedagogik och följs sedan av en presentation av temanumrets fem bidrag. Därefter diskuterar jag, med utgångpunkt i bidragen, två mer generella teman inom berättelseforskning som handlar om relationen mellan berättelser och erfarenhet samt mellan berättande och identitet.
\end{abstract}

\section{BERÄTTELSENS DANANDE OCH UTMANANDE FUNKTIONER}

Berättelser är ett kulturellt verktyg vi människor har för att förstå och skapa ordning i och för oss själva, varandra och den värld vi lever i (Bruner, 1987), och som sådant ett intressant fenomen att studera inom pedagogisk forskning, där påverkans- och utvecklingsprocesser som lärande, socialisation, styrning, meningsskapande och identitetsformering är centrala kunskapsobjekt. Bruner (2008, s. 45) gör oss uppmärksamma på berättelsens betydelse i bevarandet av kulturell och social ordning genom vad som (lite slarvigt) kan kallas en diskursiv kulturell reproduktion. 
Indeed, we are beginning to understand how cultures rely upon narrative conventions to maintain their coherence and to shape their members to their requirements. Indeed, commonplace stories and narrative genres even provide a powerful means whereby cultures pass on their norms to successive generations. Narrative is serious business.

Grupper, från familjer till nationer, hålls samman genom att både reproducera gamla och producera nya berättelser om det som förenar dem och det som skiljer dem från andra (Riessman, 2005). En berättare, vare sig det är en individ, grupp, en organisation eller en statsmakt, berättar om förflutna eller framtida händelser som i berättelsen organiseras, kopplas samman och värderas på ett visst sätt för att berättelsens poäng ska bli meningsfull för en specifik publik (Czarniawska, 2000). Samhällsinstitutioner, som till exempel skolan eller familjen, bärs upp och är bärare av kulturellt dominerande berättelser om hur världen är/bör vara organiserad och om vilka vi är och hur vi förväntas agera i olika sammanhang. Sjöstrand (1968, s. 22) pekade på att det $\mathrm{i}$ alla samhällen och kulturer "föreligger en ständig påverkan på människorna $\mathrm{i}$ avsikt att dessa genom inlärning skall på bästa möjliga sätt formas $\mathrm{i}$ överensstämmelse med vad man inom ifrågavarande samhälle och kultur önskar göra dem till”. Genom att studera berättelsens danande kraft i olika pedagogiska sammanhang kan vi förstå denna ständiga påverkan lite bättre. Här blir identifieringen av kulturellt vedertagna berättelser viktig.

Kulturellt vedertagna berättelser kan förstås som standardberättelser med igenkännbara karaktärer, händelseförlopp och upplösningar (Blomberg \& Welander, 2017). Sådana berättelser är som mest kraftfulla när de ”(...) become perceived as natural, essential and given." (Andrews et al., 2015, s. 143). Ett exempel på en sådan berättelse kan vara den om kärnfamiljen. Jag vågar mig på att påstå att många unga människor som växer upp i Sverige idag, oavsett social klass, etnisk bakgrund, religion och sexuell identitet, lever den kulturellt vedertagna berättelsen om att träffa en annan, bli förälskad, dela ett hem, skaffa barn, och därmed leva ett gott liv. Att istället fortsätta leva tillsammans med sina egna föräldrar under vuxenlivet betraktas ofta, båda av personen själv och av andra, som onaturligt och kanske till och med sjukligt avvikande. Denna och andra kulturellt vedertagna berättelser är förstås i ständig förändring och utmanas för att i förlängningen kanske helt förlora sin betydelse. En berättelse är bara kulturellt vedertagen så länge den återberättas.

Utifrån detta perspektiv kan berättelsen som form för meningsskapande ses som ett slags kulturellt transportmedel för både, ett bevarande och ett utmanande av normer, värden och identiteter. Allt, från de sagor vi läser för barnen i förskolan till de serier vi själva följer via olika streamingtjänster på kvällen, påverkar oss genom att de $\mathrm{i}$ form av berättelser presenterar möjliga sätt att vara människa och erbjuder tänkbara framtider där vi kan bli något 
annat än vi är idag. Med andra ord så föds vi alla in, växer upp, lever och dör i sammanhang som genom kulturellt vedertagna berättelser erbjuder möjliga identiteter och sätt att leva. Jag har svårt att föreställa mig ett fungerande samhällsliv utan sådana bevarande och sammanhållande berättelser. Samtidigt kan sådana, om de står oemotsagda, också fungera alltför begränsande och i värsta fall till och med förtryckande.

Berättelsen kan även ses som ett diskursivt verktyg för motstånd mot just det vedertagna och förväntade (Bamberg \& Andrews, 2004). Alternativa berättelser kan på olika sätt göra motstånd mot dominerande berättelser (Andrews, 2002). Drivkraften bakom ett berättande kan handla om att individens eller gruppens erfarenheter och framtidsdrömmar inte passar inom ramarna för vad kulturellt vedertagna berättelser erbjuder som normala eller önskvärda liv. Berättelser är ett kraftfullt kulturellt verktyg för ett bevarande av en etablerad ordning, men kan också utmana det för givet tagna och erbjuda nya sätt att tänka och agera.

Vad är då en berättelse och varför ska vi intressera oss för detta fenomen inom pedagogisk forskning? Berättelseforskningens filosofiska rötter har bland annat spårats tillbaka till Aristoteles Om diktkonsten och Augustinus Bekännelser, där Ricoeur hämtat inspiration till sin fenomenologiska teori om tid och narrativ (Ricoeur, 1984). Labov och Waletzkys (1997) och Bruners (1992) sociolingvistiska respektive psykologiska forskning om berättelsen som kommunikationsform och sätt att tänka har bidragit till vår förståelse för berättelsens referentialitet och funktion. Det finns, som väntat, lika många svar på frågan om vad en berättelse är som det finns discipliner och forskningsfält med intresse för fenomenet. Berättelsen kan studeras med fokus på innehåll, form eller funktion (Mishler, 1995), och för att kunna göra detta behöver vi identifiera en berättelse som något som skiljer sig från andra representationer av levd erfarenhet. Inom mångfalden av definitioner finns några grundläggande ingredienser $i$ vad vi ser som utmärkande för en berättelse. Enligt Hydén (1997, s. 20) finns följande centrala drag i en berättelse "(...) bändelser, som sker i ett visst sammanhang, är orsakade eller förorsakade av något (kanske av huvudpersonen i berättelsen) och upplevda av någon (exempelvis berättaren - men inte nödvändigtvis) och som framställs av någon" (se även Labov \& Waletzky, 1997). Utöver dessa centrala drag utmärks berättelser av att de levererar en poäng som blir betydelsefull för berättare och publik i det sammanhang där berättandet fyller en funktion. Berättare berättar för att åstadkomma något (Mishler, 1999). Som jag ser det, är det just berättelsens funktionella aspekter som blir särskilt intressanta inom pedagogik som kunskapsområde $\mathrm{i}$ och med att vi påverkas och påverkar genom att ta del av eller berätta berättelser.

Detta temanummer presenterar fem bidrag som alla, på olika sätt, presenterar pedagogisk forskning där muntliga berättelser och/eller berättande utgör studieobjekt. Samtliga bidrag placerar sig dessutom inom teoretiska ansatser 
där muntligt berättande ses som en socialt situerad handling; det vill säga att man genom berättande åstadkommer något i relation till andra i ett specifikt sammanhang (Mishler, 1999; Peterson \& Langellier, 2006). Detta medför att berättelsers innehåll och berättandets sociala funktioner blir mer uppmärksammade i detta temanummer än dess form.

Nedan följer en kort presentation av varje bidrag. Därefter lyfter jag fram gemensamma nämnare i bidragen i en diskussion kring två mer generella aspekter av berättelser i pedagogisk forskning; Liv, erfarenhet och berättelser samt Berättande, positioner och det vedertagna.

\section{TEMANUMRETS BIDRAG}

Alla fem artiklar rör sig i eller i närheten av skolans värld, och behandlar spänningar mellan det vedertagna och det utmanande. De kunskapsobjekt som studeras med hjälp av berättelser är pedagogiska processer som legitimering, läsning, identitetsformering, ansvarsfördelning, betygsättning, undervisning, m.m. Bidragen presenteras i den ordning de har i temanumret.

Svahns och Hallséns bidrag handlar om relationer mellan privata läxhjälpsföretag och det etablerade skolsystemet i Sverige. Artikelns syfte är att undersöka hur privata läxhjälpsföretag söker legitimitet för sina tjänster och sin existens i gränslandet av ett etablerat skolsystem. Med utgångspunkt i ett perspektiv på berättelser som meningsskapande social praktik analyseras intervjuer med företrädare för två olika läxhjälpsföretag som organisationsberättelser. Analysen visar hur olika organisationsidentiteter tar form genom hur organisationernas verksamheter positioneras i relation till den ordinarie skolan, till normer och värden, samt till växlande förutsättningar på en läxhjälpsmarknad. I resultatet framträder en bred repertoar av organisationsidentiteter där berättelserna positionerar läxhjälpsföretagens verksamheter inom ramarna för det etablerade skolsystemet och samtidigt distansera sig från detsamma. Det senare blir kanske främst tydligt i representanternas anspråk på att deras verksamheter både är en förlängning av skolans verksamhet men samtidigt något annorlunda. Sammanfattningsvis visar studien hur organisationsidentitet inte kan förstås som något statiskt svar på frågan om vad en organisation är eller vill vara, utan snarare som något som hela tiden omkonstrueras i relation till omgivande förutsättningar.

I Asplunds artikel fokuseras läsning bland män i svensk skogsbygd. Genom livsberättelseintervjuer med fokus på en ung arbetarmans berättade erfarenheter och minnen av skolans läsundervisning och andra typer av läsning framträder en läsarhistoria som delvis utmanar en vedertagen läsdiskurs. Analysen visar även hur denna läsarhistoria är en produkt av den lokala och historiska kontext som berättaren växt upp och lever i. Artikeln synliggör hur läsning görs till en socialt och kulturellt accepterad praktik inom en lokalt förankrad maskulin arbetarklasskultur. Detta sker genom processer där en viss sorts läs- 
ning kopplas till konkreta fysiska handlingar och införlivas $i$ en muntlig berättartradition. Studien riktar ljuset mot frågor om vad läsning är och på vems eller vilkas villkor, samt om vem som är eller inte är en läsare. Studien illustrerar också hur möjligheter att diskutera läsningens vad, hur och varför i skolans läsundervisning riskerar att gå förlorade i en läsdiskurs som betonar läsning av pappersburen typografisk text. En läsdiskurs som i värsta fall riskerar att utestänga andra, alternativa sätt att läsa och skapa mening i mötet med olika typer av texter.

Ljung Egelands bidrag handlar om migration, språk och identitet och fokuserar på emotionella positioneringar i grundskoleelevers berättelser om sina relationer till språk. Artikeln syftar till att bidra med kunskap om modersmålsundervisning i skolan, samt om engagemang i språkinlärning bland elever med migrationsbakgrund. Utifrån ett perspektiv på berättelser som socialt situerade handlingar och identitetsframträdanden har sex livsberättelseintervjuer genomförts med två elever med migrationsbakgrund som bor och går i skolan på mindre orter i Sverige. Intervjuerna har haft ett brett anslag fokuserat på elevernas migrationshistorier, famili, skola, kamrater och var de bor. Två berättelser om språk och modersmål har valts ut ur detta material för denna artikel. Resultatet av en positioneringsanalys med fokus på emotionella positioneringar i både tal och gester visar att uttryck för glädje och stolthet framträder ur berättelserna, men också mer ambivalenta känslor kopplade till modersmålet och modersmålsämnet i skolan. Eleverna beskriver hur modersmålsundervisning i skolan är viktig för dem på sätt som göra att den framstår som en språkligt och kulturellt identitetsstärkande praktik.

I Löfgrens artikel presenteras en studie om vilka konsekvenser en försöksverksamhet med att införa betyg i årskurs 4 kan få för grundskoleelever som är i behov av särskilt stöd. Studien baseras på intervjuer med skolpersonal och elever från en skola, som alla berättar olika versioner av en händelse som involverade en specifik elev på skolan. Eleven i fråga blev, enligt berättelserna, mycket ledsen efter att ha fått sitt första betyg och bytte skola. Med utgångspunkt $\mathrm{i}$ teorin om institutionella minnen kan dessa berättelser ses som olika uttryck för en "bullrig tystnad", något obekvämt och icke önskvärt för en institution. Utifrån ett perspektiv på berättelser som socialt situerade handlingar och identitetsframträdanden, analyseras rektorns, speciallärares, lärares och elevers olika berättelser om denna händelse. Resultatet av en narrativ positioneringsanalys av berättelserna visar att ansvaret för händelsen förläggs på olika parter i och utanför skolan, samt att eleven positioneras som bärare av olika prestationsemotioner. Resultaten visar också att den bullriga tystnaden som framträder i de olika berättelserna om eleven som bytte skola ställer rationalen om det fria skolvalet mot rationalen om en skola för alla. Diskussionen fokuserar på frågan om vem som är ansvarig för elever i behov av stöd och för likvärdigheten i en marknadiserad skola för alla. 
I Henricssons artikel presenteras en studie av lärares spontana muntliga berättande i undervisning och dess didaktiska innebörder. Utifrån ett fenomenologiskt perspektiv med fokus på den levda kroppens betydelse för muntligt berättande analyseras en videoinspelning där en lärare hanterar en situation under en lektion genom att berätta. Fenomenet - lärares spontana berättande - diskuteras i artikeln som ett uttryck för pedagogisk takt, det vill säga en kvick bedömning och ett spontant agerande $\mathrm{i}$ undervisningssituationer baserat på lärares erfarenhet och känsla. Resultatet visar att ett improviserat muntligt berättande riktar elevernas uppmärksamhet från observerbara faktiska föremål, modeller och förhållanden till narrativa metaforer och händelseförlopp som skapas av elevernas föreställningsförmåga. En pedagogisk berättande takt ställer krav på lärarens situationstrygghet, vilket står i kontrast till en instrumentell syn på undervisning och lärande, där en viss metod leder till ett på förhand givet utfall. Henricssons artikel sätter ljuset på hur lärares spontana muntliga berättande kan ses som ett uttryck för berättande takt. Att bjuda in eleverna till en berättelsens värld kan, som artikeln visar, vara förenat med vissa risker men kan också ge oväntade positiva didaktiska implikationer.

\section{LIV, ERFARENHET OCH BERÄTTELSER}

Två bidrag i detta temanummer presenterar pedagogisk forskning som baseras på livsberättelseintervjuer. Det är näst intill omöjligt att studera livsberättelser om man inte någon gång brottas med relationen mellan liv, erfarenhet och berättelse (Bruner, 1986). Vad är en livsberättelse i relation till de levda livserfarenheter den gör anspråk på att ge uttryck för (Karlsson, 2006)? Vad är skillnaden mellan det levda och det berättade livet? De bidrag i temanumret som baseras på livsberättelser, Asplund och Ljung-Egeland, betonar vikten av att ta utgångspunkt $\mathrm{i}$ den berättande människans erfarenheter. Asplund betonar att det handlar om berättade erfarenheter, vilket signalerar ett antagande om att berättelser inte på ett självklart sätt direkt återspeglar tidigare erfarenheter. Man kan istället, som Pérez Prieto (2006), betrakta en livsberättelse som en av flera möjliga versioner (se även Löfgrens bidrag); versioner som i grund och botten ändå bygger på berättarens livserfarenheter.

Det finns sålunda ett inslag av ofullständighet och selektivitet i berättelserna som är ofrånkomlig och inneboende i livshistorierna, som befäster deras egenskap av 'versioner' och som vi måste hålla i minnet i samband med analyserna och slutsatserna, detta även om anspråket inte är att spegla den 'sanna' och 'verkliga' historien. (Pérez Prieto, 2006, s. 15)

Om livsberättelser karaktäriseras av ofullständighet och selektivitet, är de då en värdefull empiri i pedagogisk forskning? Absolut, om vi är intresserade av 
att ta del av vad intervjupersoner ser som viktigt att berätta om. Den selektivitet som Pérez Prieto pekar ut som potentiellt problematisk inom livsberättelseforskning kan också ses som särskilt viktig och intressant. Om vi vågar ge intervjupersoner möjligheten att berätta om betydelsefulla livserfarenheter inom ett visst område så får vi ta del av vad de idag ser som betydelsefullt med det som hände då, och inte vad som framstod som betydelsefullt för oss som forskare när vi formulerade vårt projekt. Livsberättelseforskning som tar sin utgångspunkt i människors berättade erfarenheter kan med Mills (1959, s. 226) ord bidra med kunskap om "(...) the human meaning of public issues".

Ett varnande finger bör dock lyftas för att bromsa tendenser att romantisera den personliga livsberättelsen som något mer autentiskt eller sant än andra representationer av erfarenheter och identiteter (Atkinson \& Delamont, 2006). Ambitioner att "ge röst" åt marginaliserade grupper genom berättelseforskning riskerar att reducera sociala problem till personliga livsöden, om dessa inte kontextualiseras (Goodson, 1997). Det är också viktigt att vi som forskare ser vår egen medverkan i det berättande vi studerar (Mishler, 1999; Karlsson, 2017). Vi bör reflektera över hur både, den lokala kontexten i möten med till exempel intervjupersoner och den globala kontexten som utgörs av våra forskningsprojekt, villkorar vilka berättelser som blir möjliga att berätta och höra (Helsig, 2010; Karlsson \& Pérez Prieto, 2012).

\section{BERÄTTANDE, POSITIONER OCH DET VEDERTAGNA}

Flera bidrag fokuserar på berättande som identitetsframträdanden (Mishler, 1999), vilket studeras genom positioneringsanalyser (Davies \& Harré, 1990; Bamberg, 1997; Depperman, 2015). Idén om den essentiella och över tid stabila identiteten utmanas idag av forskare som intresserar sig för hur identiteter förhandlas i olika typer av berättelser, allt ifrån tillbakablickande berättelser om ett helt liv (Freeman, 2010) till de små berättelser vi berättar för varandra i vardagen (Ochs \& Capps, 2001; Karlsson, 2013). Oavsett vilka typer av berättelser vi fokuserar på i vår forskning så medför ett fokus på identitetseller subjektspositioner att kulturellt vedertagna berättelser aktiveras och att de förväntade och för givet tagna positionerna inom ramen för dessa aktualiseras av både berättare och åhörare.

Ett exempel på hur kulturellt vedertagna berättelser verkar, presenteras av Spånberger Weitz och Karlsson (2020). Studien fokuserar på delat föräldraskap mellan biologiska föräldrar och fosterföräldrar och baseras på intervjuer med föräldrar vars barn placerats i fosterhem. Författarna visar, genom en positioneringsanalys, hur föräldrars berättelser om svårigheter med delat föräldraskap filtreras genom en kulturellt vedertagen berättelse om den ständigt närvarande modern (se även Andrews, 2002). På liknande sätt utforskar flera bidrag i detta temanummer mellanrummet mellan det levda livet 
och de kulturellt vedertagna berättelser samhällen erbjuder. Det kan som i Asplunds, Ljung-Egelands och Löfgrens bidrag handla om att studera hur berättare positionera sig själv och/eller andra i relation till kulturellt vedertagna berättelser om läsning, modersmål eller betyg. Det kan också, som i Svahns och Hallséns bidrag, handla om att som berättare positionera den läxhjälpsorganisation man leder eller arbetar i som mer eller mindre starkt knuten till skolans uppdrag, normer och värderingar. Denna typ av spänningsförhållande aktualiseras även i Henricssons bidrag. Här beskrivs lärares spontana berättande som en undervisningsmetod förenad med vissa didaktiska risker, och i och med detta som ett motstånd mot en kulturellt vedertagen berättelse om fördelen med evidensprövade och därmed replikerbara undervisningsmodeller.

\section{SUMMERING}

Summa summarum, berättelsens danande och utmanande funktioner gör den till ett intressant kunskaps- och studieobjekt inom det pedagogiska kunskapsområdet. Vi som studerar berättelser och berättande delar detta intresse med forskare inom många andra discipliner där andra aspekter av berättelser och berättande fokuseras. Enligt Clandini och Rosiek (2006) bedrivs berättelseforskning utifrån vitt skilda grundantaganden om kunskap och verklighet, vilket får konsekvenser för på vilket sätt berättelser ses som intressanta kunskaps- och studieobjekt. Vad som dock, enligt författarna, förenar berättelseforskare inom olika traditioner är framför allt ett fokus på levd erfarenhet, vilket medför ett gemensamt intresse för temporalitet, socialitet och plats. Om jag här på slutet får ta ut svängarna lite så vill jag påstå att berättande kan ses som en resa i tid och rum. Genom berättelser kan vi besöka platser, personer och känslor förknippade med dessa i vårt förflutna eller i en föreställd framtid. Det är svårt att föreställa sig ett liv utan berättelser. Vad skulle vi prata om och hur?

De sätt på vilka vi människor använder berättelsen kan liknas vid hur vi använder karta och kompass när vi orienterar i skogen. Dessa kulturella redskap ger oss en uppfattning av var vi har varit, var vi är nu, vart vi är på väg och vad vi kan förvänta oss att möta på vägen dit och när vi kommer fram. Samtidigt motsvarar kartans representation av världen aldrig det vi möter när vi tar oss fram i skog och mark, och kompassen kan bara hjälpa oss om någon annan lärt oss att använda den på rätt sätt. 


\section{REFERENSER}

Andrews, Molly (2002). Memories of mother: Counter-narratives of early maternal influence. Narrative Inquiry, 12(1), 7 - 27. https://doi.org/10.1075/ni.12.1.04and

Andrews, Molly, Kinnvall, Catarina, \& Monroe, Kristen (2015). Narratives of (In)Security: Nationhood, Culture, Religion, and Gender: Introduction to the Special Issue. Political Psychology, 36(2), 141-149.

http://www.jstor.org/stable/43783850

Atkinson, Paul, \& Delamont, Sara (2006). Rescuing narrative from qualitative research. Narrative Inquiry, 16(1), 164-172. https://doi.org/10.1075/ ni.16.1.21atk

Bamberg, Michael G.W. (1997). Positioning between structure and performance. Journal of Narrative \& Life History, 7(1-4), 335-342. https://doi.org/10.1075/jnlh.7.42pos

Bamberg, Michael G.W., \& Andrews, Molly (2004) (red.). Considering counternarratives: Narrating, resisting, making sense. John Benjamins.

Blomberg, Helena, \&. Welander, Jonas (2017). 'Kör tills du brakar, sedan kastar vi ut dig om du inte flyr innan' - Socialsekreterares berättelser om uppbrott från arbetsplatsen. Socialvetenskaplig tidskrift, 24(1), 19-37 https://doi.org/10.3384/SVT.2017.24.1.2401

Bruner, Edward M. (1986). Experience and Its Expressions. I V.W. Turner, \& E.M. Bruner (red.), The Anthropology of Experience (s. 5-30). University of Illinois Press.

Bruner, Jerome S. (1987). Life as narrative. Social Research, 54(1), 11-32.

Bruner, Jerome S. (1992). The narrative construction of reality. I H. Beilin, \& P. B. Pufall (red.), Piaget's theory: Prospects and possibilities (s. 229-248). Lawrence Erlbaum Associates, Inc.

Bruner, Jerome S. (2008). Narrative, culture and mind. I D. Schiffrin, A. De Fina, \& A. Nylund (red.), Telling stories: Language, Narrative, and Social Life (s. 45-49).

Georgetown University Press.

Clandinin, Jean D., \& Rosiek, Jerry (2007). Mapping a Landscape of Narrative Inquiry: Borderland Spaces and Tensions. I D. J. Clandinin (red.), Handbook of narrative inquiry: Mapping a methodology (s. 35-75). Sage Publications, Inc. https://doi.org/10.4135/9781452226552.n2

Czarniawska, Barbara (2000). The uses of narrative in organization research. (GRI Report 2000:5), Göteborg University. http://hdl.handle.net/2077/2997

Freeman, Mark P. (2010). Hindsight: The promise and peril of looking backward. Oxford University Press.

Davies, Bronwyn, \& Harré, Rom (1990). Positioning: The Discursive Production of Selves. Journal for the Theory of Social Behaviour, 20, 43-63. https://doi.org/10.1111/j.14685914.1990.tb00174.x 
Deppermann, Arnulf (2015). Positioning. I A. De Fina, \& A. Georgakopoulou (red.), The Handbook of narrative analysis (s. 369-387). John Wiley \& Sons Inc. https://doi.org/10.1002/9781118458204.ch19

Goodson, Ivor F. (1997). Representing teachers. Teaching and Teacher Education, 13(I), I 11-117.

Helsig, Sarah (2010). Big Stories Co-Constructed: Incorporating Micro-Analytical Interpretive Procedures into Biographical Research. Narrative Inquiry, 20(2), 274295. https://doi.org/10.1075/ ni.20.2.03hel

Hydén, Lars-Christer (1997). De otaliga berättelserna. I L-C. Hydén, \& M. Hydén (Red.) Att studera Berättelser. Sambällsvetenskapliga och medicinska perspektiv (Första uppl., s. 9-29). Liber.

Karlsson, Marie (2013). Emotional identification with teacher identities in student teachers' narrative interaction. European Journal of Teacher Education, 36(2), 133-146. 10.1080/02619768.2012.686994

Karlsson, Marie (2017). Att studera berättelser som socialt situerade handlingar. I R. Sorly, \& B.H. Blix (red.), Fortelling og forskning - narrativ teori og metode i tverrfaglig perspektiv, (171-179). Orkana Akademisk.

Karlsson, Marie, \& Pérez Prieto, Héctor (2012). Professional identities in retired teacher educators' life stories - The global and local contexts of life story interviews. I I. F. Goodson, D. Stephens, \& A. Loveless (red.), Explorations in Narrative Research (s.141-152). Sense Publishers.

Labov, William \& Waletzky, Joshua (1997). Narrative analysis: Oral versions of personal experience. Journal of Narrative \& Life History, 7(1-4), 3-38. https://doi.org/10.1075/jnlh.7.02nar

Mills, Charles W. (1959). The Sociological Imagination. Oxford University Press.

Mishler, Elliot G. (1995). Models of narrative analysis: A typology. Journal of Narrative \& Life History, 5(2), 87-123. https://doi.org/10.1075/jnlh.5.2.01 mod

Mishler, Elliot G. (1999). Storylines. Craft Artists' Narratives of Identity. Harvard University Press.

Ochs, Elinor, \& Capps, Lisa (2001). Living narrative: Creating lives in everyday storytelling. Harvard University Press.

Pérez Prieto, Héctor (2006). Historien om räven och andra berättelser. Om klasskamrater och skolan på en liten ort - ur ett skol- och livsberättelseperspektiv. Karlstad University Studies 2006:52.

Peterson, Eric E., \& Langellier, Kristin M. (2006). The performance turn in narrative studies. Narrative Inquiry, 16(1), 173-180.

https://doi.org/10.1075/ni.16.1.22pet

Ricoeur, Paul (1984). Time and narrative. Vol. I. University of Chicago Press. 
Riessman, Catherine K. (2005). Narrative Analysis. I N. Kelly, C. Horrocks, K. Milnes, B. Roberts, \& D. Robinson (red.), Narrative, Memory \& Everyday Life (s. 17). University of Huddersfield.

Sjöstrand, Wilhlem (1968). Pedagogiska grundproblem i bistorisk belysning. Gleerups.

Spånberger Weitz, Ylva, \& Karlsson, Marie (2020). Professional or authentic motherhood? Negotiations on the identity of the birth mother in the context of foster care. Qualitative Social Work, 20(3), 703-717.

https://doi.org/10.1177/1473325020912815 